\title{
The Importance of the Hanon Piano Fingering in Piano Teaching
}

\author{
Jie BAI \\ No.18 of dianzi road Yanta District Xi'an Shaanxi province, Music Department of Xi'an Shiyou \\ University
}

www.530299786@qq.com

Keywords: Hanon piano; Fingering Practice; teaching.

\begin{abstract}
This paperused the literature method to discuss the importance of Hanon Piano Fingering in piano teaching. Hanon Piano Fingering popularized the basic technique of piano training, so that we can solve the laws of the progress of playing piano effectively.
\end{abstract}

\section{Introduction}

The Hanon Piano Fingering(hereinafter referred to as the Hanon)is a piano textbook of finger exercises which is composed by the famous French musician Charles Louis Hanon in 1871. Hanon is a famous French organist, pianist and piano pedagogue in 19th century. He accepted the church music training from a young age and later he played organ in the church and acted as a chorus master, teaching piano and vocal music, and accumulated a wealth of teaching experience. Hanon piano exercises popularized the basic techniques of piano. In this textbook, Louis Hanon used a very simple way, scientific arrangement of finger exercises, its purpose is to make the two hands to balanced development, each finger flexible, powerful, and independent, and flexible wrist relax, eventually left and right hand has the same skill and dexterity, have the same ability.

\section{The characteristics of the textbook of Hanon Piano Fingering}

Many teachers think that Hanon exercises influence the speed of piano teaching, but if there is on Hanon Piano Fingering practical and strong practice, our finger will not have independence, flexibility, and good attitude. It is very important to have strong and consummate skill in the process of learning the piano. In addition, the practice textbook which only has piano technique is lacking in music and played a single method, students especially beginners will be boring and have tired of emotions after a long practice. This requires the piano teacher to take some effective methods and use it flexible to mobilize the enthusiasm and initiative of students during the boring practice, and then let the students find the pleasure of piano. To establish a good sound and play concept is not only a foundation of practices the Hanon exercises but also the essential condition of piano teaching. Playing the piano is playing sound, the sound and tone is good or not determines the basic skills of a player, playing level and playing skills. A great performer must have a good ear, and have a super ability to identify his own playing tone. Hanon Piano Fingering is a good medicine to solve and training good finger ability and solid basic skills, it is a great treasure for all piano education workers and children who study and training piano very hard. Second, is to build a good play, because Hanon is to teach students to complete the technical training of a special set of exercises within a relatively short period of time, not only is the activity of fingers.

Each of Hanon's exercises is easy to read from a spectral perspective. The purpose of the author's design is to clear the barriers of reading for the learners, and quickly enter the skilled stage. However, it is so, but let some practitioners develop a sloppy, arbitrary practice habits, coupled with sound and fingering is a regular, fixed down, it is easy to make the brain in a state of paralysis, make practitioners slowly develop the habit of not thinking, without clear objectives, lead to play method to errors, but also caused the wrist muscle tension, the arm is not relax, etc. 


\section{The Characteristics of the Playing of Hanonpiano Practice}

So how do you play Hanonetudes? First of all, we should understand the whole of Hanon's book and establish a clear purpose. The book is divided into three parts. The first part is to make the fingers flexible, free of restraint, smooth movement, strong and strong, uniform and uniform of the exercises, total 20. The second part: it is the advanced practice that specialized practice dozen good fingering foundation, total 20 . The third part is to overcome the technical difficulties which must be specially practiced, there are 17 . As the exercisers, first of all, you should have an understanding of the book's feed to have a purpose and a methodical practice. This is important because he is a guide to the correct play of the exercisers and the ultimate bridge to achieve the goal. In this way, the exercise can be done in this way. Break up practice, break up practice second, and carry on specific analysis to specific practice. For example, article 4 of the first stage of Hanon": first we understand the overall requirements of this stage, and the focus and difficulty are on the left hand and the right hand. 1. Break up practice, so that you can focus on the training of weak points. 2. While practicing the breakup, the first beat of the right hand while on the line, 3, 4, 5 refers to the strong treatment, the second beat the weak processing of the fingers, emphasizing the independence of 3,4 and 5 . When going down, the right hand can be used in the same way to practice, 3 , hand practice and emphasize difficult and difficult training. When practicing with your hands, focus on the 3, 4, and 5 points of your left and right hand, then pay attention to the use of the fingers together. In addition, some rhythm changes can be designed to enhance the ability of the fingers. By using different rhythm patterns to create different stresses, the ability of each finger is enhanced. To sum up, it is extremely important to read all the Suggestions on the spectrum carefully. The purpose of practicing the piano is clarified, and the efficiency is improved, and it is also prevented from blindly using the same force for every finger practice. Only from the beginning can focus attention. The careful playing of the training purpose is likely to meet the requirements and objectives discussed in Hanon's preface.

The independence of fingers is mainly the strength of the finger and the ability to stand alone. The independence of fingers is the basis of the ability of the fingers, which is required to be done at the beginning of the piano. This is the most important part of the basic skills of qin. It must be paid attention and attention from the beginning. Some students because of their own and teachers not strict, training is not in place, separate practices can also, one to the actual use of deformation out of sample. Then we can refer to"Hanon" for a targeted exercise. Each of Hanon's exercises are clearly defined, and this one is focused on which finger to train. The correct way to play "Hanon" is to allow the force to reach its fingertips relatively centrally, with its arms, elbows, wrists and hands. The fingertip must be a concentrated burst point and control point. So be sure to follow the following points: stand with your fingertips, hold your palms in a circular shape, relax your wrists, relax your shoulders, and use your waist to support them.

Finger running on a keyboard is an important technique. The running training of the scales and arpeggios in "Hanon" is carried out with specific practice. First put the mentality smooth slow practice, slowly ponder refers to the time and the shape of a palm open appropriate, cultivate our touch sensitivity, slowly raise refers to and turn refers to the speed, but also pay attention to the big arm too stiff. The reasons for running behind are also problems with finger adhesion. The stickiness of the fingers is not lost until the last one is lost, the last one is not lost, the last one appears, and the two sounds overlap. The resulting sound is short of particle and lacks of liquidity. This is caused by the slow moving of the fingers. So make sure your finger is playing and the action of the key, that is, when the sound of a finger plays down, the first finger should be lifted immediately. The reason for this adhesion is that the fingers are soft, except for the inertia of the fingers. So we need to fix the joint of our fingertips so that the strength is at our fingertips, so that we can effectively improve the problem of sound deficiency and the lack of strength in the fingertips. We can practice with the high-lift finger touch in "Hanon" to get the problem targeted. In addition, the uniformity of fingers is also the key to the movement of fingers. We can vary the rhythm of the play according to the repertoire of "Hanon". Make crotchet quaver, for example, on the basis of the rhythm of each section plus dotted notes, syncopation, such as playing method, training each finger and touch 
feeling, to make every sound play more evenly, can effectively improve the speed, improve the ability to run your fingers, can also be in the works of more exquisite.

\section{Conclusion}

Good finger control comes from good finger basic skills and finger control ability. Piano music works of the strength, melody, timbre, level, style of work, thanks to playing skill when using a variety of techniques to complete. The strength, melody, timbre, level and work style of music of the piano are accomplished by using all kinds of techniques with high proficiency. The so-called high proficiency, means that in the process of playing the piano, you can just use and deal with a variety of control. In fact, I think that the finger on the keyboard control actually comes from our psychological control. The basic skills that we trained earlier helped us to have a great deal of skill, but in the climax of skilled technology are only external, It just services for music. When you have a profound understanding of music works and grasping, and a strong psychological control ability, you can achieve the perfect technology and music, harmony and unity, this is the success of the performance of the works of thoughts and feelings and the perfect interpretation of the work. How can you have a beautiful timbre? Piano works playing good or bad, from the outside, the piano is really an important factor. In piano working. But for a general piano, you can also pursue a beautiful tone. It depends on our own players for the touch of control and sentiment. I think if there is no good touch method, it will not come out of the beautiful tone. a variety of methods of touching can also bring different changes in the timbre. So it's very important to touch the keys.

We can change the different practice methods according to "Hanon" in the practice. Such as staccato, continuous and jumping, to cultivate the feeling of different touch keys and sound changes, so that we can guess and deduce the performance more accurately in the future performance. Finally, emotion is also an issue that cannot be underestimated. Many students in the practice of piano did not do the heart of the relaxation, causing the body also to be rigid because of excessive tension, the sound is very pale and rough. We can find fun in "Hanon", teachers can also use different playing methods. Such as Staccato, dotted note.in training students interest at the same time, but also exercise the function of the fingers, so that the works played more singing. Piano development to today, various levels of pianist level are not poor. Teachers can do is to help us understand the rules of piano analysis, to help us sum up more scientific and more targeted practice piano methods to improve our level and ability, and to guide us to study consciously, analysis and summary, to solve the problem of our own and in the process of playing the piano, to find the universal law of the piano in the change and irregular. We don't play the piano as much as we can. The harder it is, the better it is. Instead, it is better to analyze and summarize the works in practice, and to carefully study the style of the works.

\section{References}

[1] Wang Peiling. The importance of the training of hardon piano practice[J]. Journal of Liaoning Teachers College (Social Sciences Edition), 2016 (3): 25-26.

[2] Feng Fan. "Hannon piano practice fingertips" and "Schmidt piano finger practice" technique analysis[D]. Xinjiang Normal University, 2016.

[3] Jiang Peilin. On the piano teaching "Hannon piano practice fingering"[J]. Yellow River Voice, 2016, (9): 33-34.

[4] Huang Xiaodan. Research on the management status and development strategies of yoga venues in jishou city from the perspective of yoga culture[D]. Hunan Normal University, 2015.

[5] Nana. Multi-dimensional analysis of the haunon piano training method[J]. Journal of shangqiu normal university, 2014,30(8):135-137.

[6] Zhao Tongyi. Hahan piano practice fingertip teaching method[J]. Examination (Theory and Practice), 2014, (3): 50-51. 